\title{
THE SURGEON AND ULCERATIVE COLITIS
}

\author{
By John Devine, M.S.(Melb.), F.R.C.S.(Eng.), F.R.A.C.S., F.A.C.S. \\ Surgeon to Out-Patients, Royal Melbourne Hospital
}

We who study Nature and her behaviour are united as a brotherhood by our search for truth. The examinee studying for a higher degree can take comfort therefore in the thought that he is not compelled to learn man-made classifications or rules, which differ from textbook to textbook, but is judged at examination by what he knows of conditions occurring in living patients.

The present article is based on:-

(I) The combined experience of my father and myself, including 24 cases where sub-total colectomy was performed for ulcerative colitis in recent years.

(2) The clinical records of 100 consecutive patients treated at the Royal Melbourne Hospital (which had an average of approximately 420 occupied beds) between 1937 and 1942.

(3) The collected mortality records of $34 \mathrm{I}$ cases of chronic ulcerative colitis treated at the three main public hospitals in Melbourne over a period of ten years to 1942 .

\section{Definition}

By ulcerative colitis is meant that disease of the colon and rectum which is characterized by:-

Diarrhoea with the passage of blood and mucus in the stools.

Characteristic ulceration of the colon.

The absence of the specific organisms of the dysenteries and of pathogenic parasites from the stools.

Characteristic changes on barium enema X-ray examination, more marked in late cases.

It is not to be confused with the more benign 'granular procto-colitis" from which it must be distinguished in its early stages.

The credit of being the first to describe ulcerative colitis has been given to Wilks, who published his description in 1875 (Buckstein, 1948).

\section{Importance to the Surgeon}

Cases of ulcerative colitis come to the surgeon for two reasons :-

(I) For diagnosis (a) in an emergency, as an ' acute' abdomen, or (b) as a chronic disease which has not yet been diagnosed. As ulcerative colitis may mimic a number of other diseases, he must bear in mind when seeing cases which may have appendicitis, diverticulitis, carcinoma of the colon and other such alimentary pathology.

(2) For an opinion as to treatment; for help in the decision as to whether, when and in what form surgical treatment should be undertaken.

Thus the surgeon must help to diagnose ulcerative colitis; he must help in advising the treatment of cases already diagnosed, and he must be ever on the look-out for the disease or its complications when considering the differential diagnosis of many other conditions.

\section{Incidence}

Vital statistics for the State of Victoria give some idea of the frequency of the disease; 2 इ patients died in Victoria from ulcerative colitis in the year $1947-48^{*}$ (approximate population, I,500,000, population of Melbourne and suburbs, I, 226,409).

Further evidence as to the frequency of the disease is obtained by the figures for 7,000 consecutive autopsies at the Royal Melbourne Hospital in the seven years ended 1934. R. J. Wright-Smith (1944) reported that 40 were on patients suffering from ulcerative colitis $\dagger$.

\section{Aetiology}

There is a marked difference in our knowledge of the aetiology of the two stages of the disease. In the first stage a number of sub-mucous collections of leucocytes are present together with oedema of the bowel wall. Then the collections change to small grey ulcers, which in turn coalesce to form larger ones. There is yet no unanimity of opinion as to the cause of this phase of the disease, a phase

\footnotetext{
* Among these cases there were:-three deaths following operation; three deaths in which haemorrhage from the bowel was considered to be the major cause of death; two cases in which pneumonia is mentioned as the major cause of death; one case in which it is mentioned that the patient had asthma as well as ulcerative it is men.

+ Among these were:-22 women and 18 men; six cases in which perforation had occurred with general peritonitis. two cases in which local peritonitis had occurred; 29 cases had had one or other of the complications'of ulcerative colitis.
} 
in which a primary breakdown of the defences of the bowel wall has occurred.

In the second or ' mechanical' phase secondary invaders from the bowel contents enter the bowel wall. The granulating ulcers in the bowel behave as breaches in the continuity of an epithelium anywhere in the body; the amount of scar tissue laid down depends on the time during which the ulcers remain unhealed. This is the stage of scarring, contraction, granulation tissue and secondary infection. The scars on the bowel wall are subjected to infection and repeated trauma from the faeces, and are therefore peculiarly liable to break down and reform ulcers. At this stage, complete cure is improbable. We can only hope that a specific remedy will shortly be found whereby the second stage will be avoided.

The reader is referred to Monaghan (1944) for a review of the possible aetiological factors of chronic ulcerative colitis.

\section{Modes of Onset}

There is a gradation in the types of onset from the acute, fulminating and severely toxic type which may progress from first symptom to death within a few weeks, to cases where the onset is insidious and the condition progresses through many years. In the first type of onset the toxaemic or general manifestations are most marked, but in other cases local manifestations of the disease may be more striking. While the most characteristic finding is that there are exacerbations and remissions, a few cases progress without remission. Bargen (1943) reported that in 871 consecutive cases there were $2 \mathrm{I}$ who died in their first and fulminating attack, while' $5 \mathrm{I}$, after remaining ' mild ' fof months or years, became fulminating in character and died despite medical or surgical

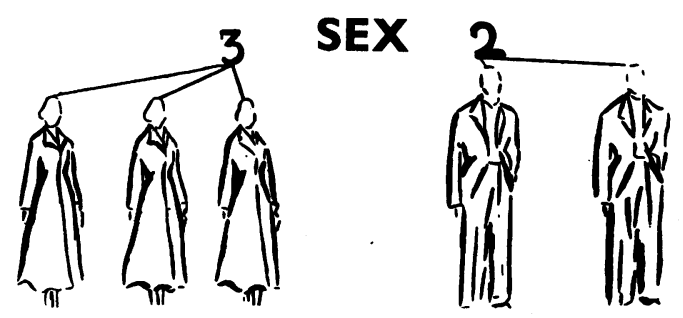

Fig. 1 .-Sex incidence.

treatment. By far the largest number of patients had an insidious onset.

\section{Types of Patient}

Most patients are between 20 and 25 y 5 r.rs of age and only II of the 100 case histories stuared in detail were outside this age group (Fig. 19). - There were three females to every two males (Fig. I).

Patients tended to be impressionable, hyperemotional and introspective. As an example of this characteristic introspection, one of our patients, K.P., a boy 19 years old, while at home awaiting the second stage of sub-total colectomy, made his mother stand on a chair beside his bed and take a photograph of his abdomen to show the temporary non-acting ileostomy and sigmoidostomy openings.

This contrasts with the findings of Kirsner, et al. (1948), who found 26 of 100 patients remembered some emotional stress prior to the onset of the disease, and with Murray (1930), who found a close association between the onset and preceding difficult psychological situations, most commonly conflicts concerned with marriage. In the 100 Royal. Melbourne Hospital patients

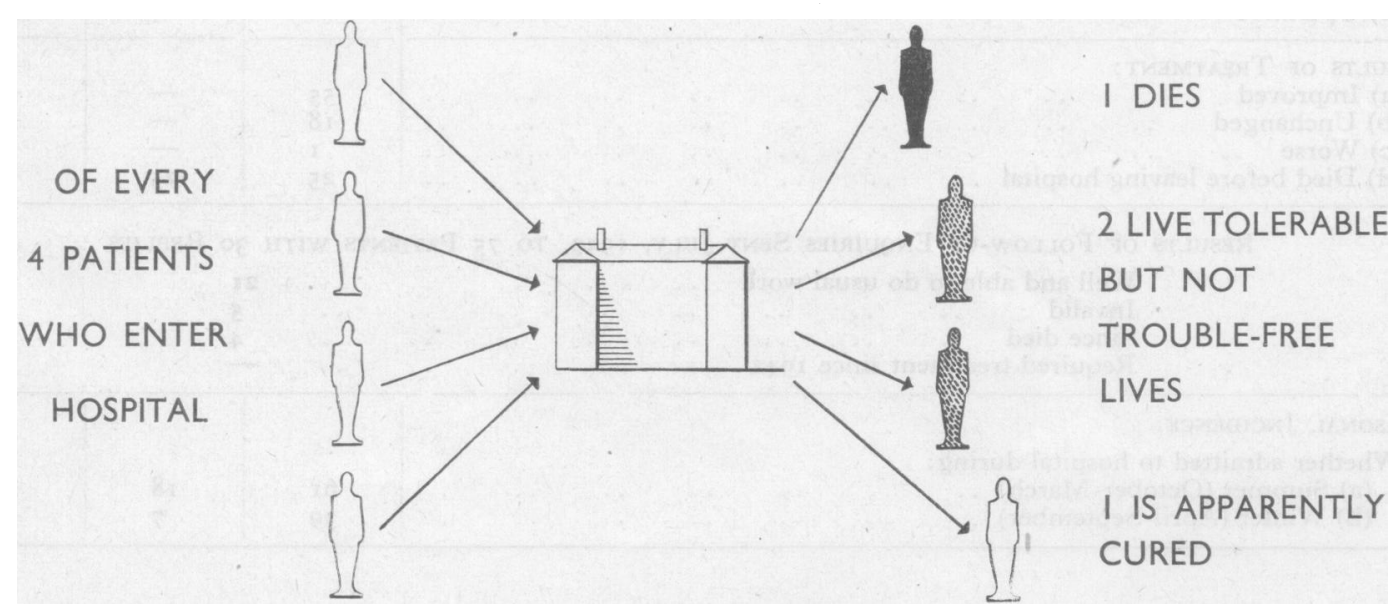

Fig. 2.-Showing results of treatment. 
TABLE I

Showing Results of a Study of ioo Consecutive Case Histories of Patients Treated at the Royal Melbourne Hospital Between 1937 and 1942

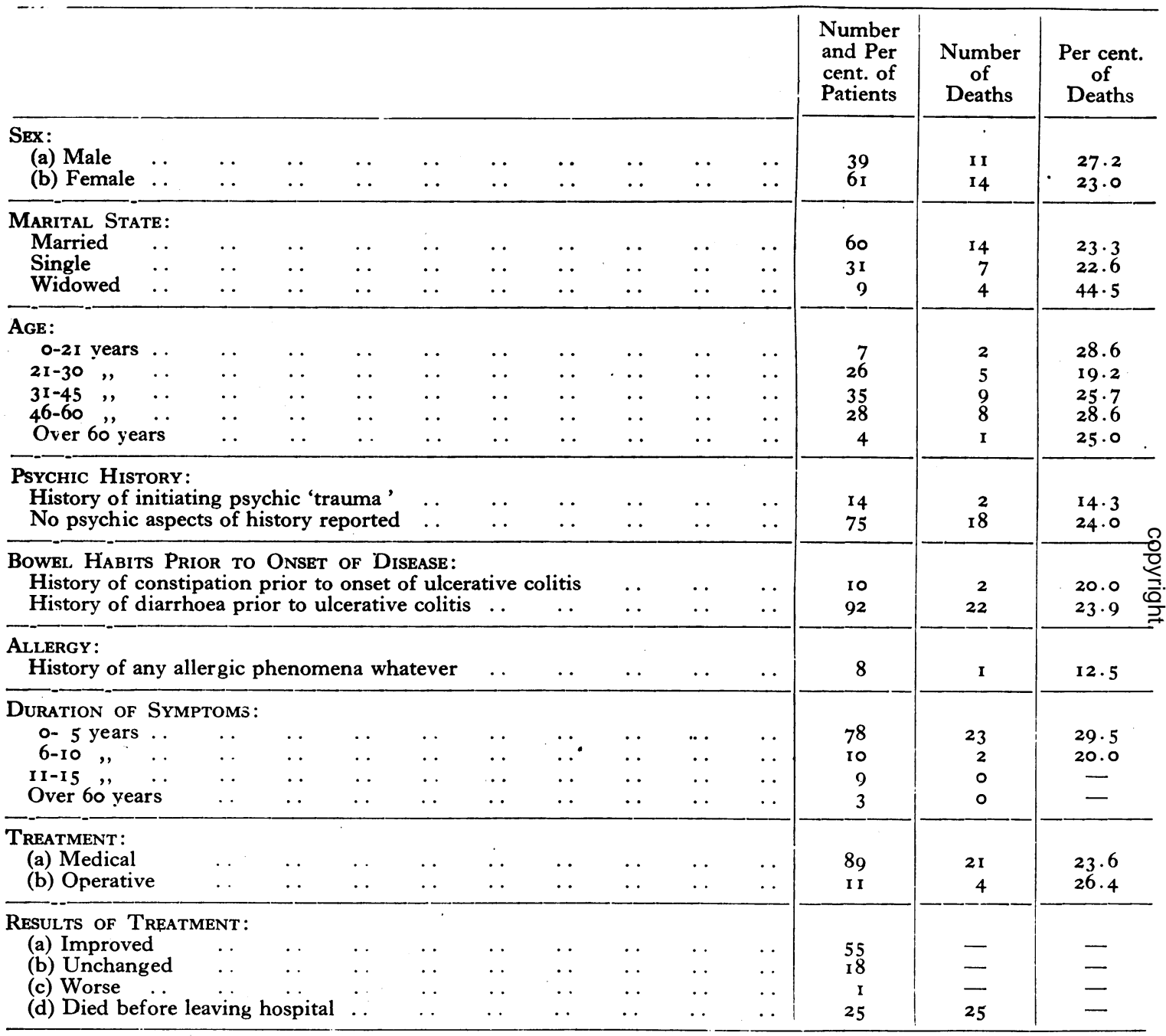

Results of Follow-up Enquiries Sent July, 1949, to 75 Patients with 30 Replies

Well and able to do usual work $\quad \ldots \quad$.

Invalid

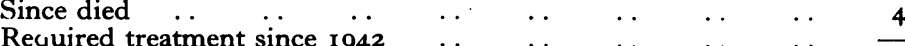

TEASONAL INCIDENCE:

Whether admitted to hospital during:

(a) Summer (October-March) ..

(b) Winter (April-September) ..

\begin{tabular}{ccccc|c}
$\cdots$ & $\cdots$ & $\cdots$ & $\cdots$ & \\
\hline & & & & & \\
$\cdots$ & $\cdots$ & $\cdot$ & $6 \mathrm{r}$ & r8 & - \\
& 39 & 7 & -
\end{tabular}


studied, $3 \mathrm{I}$ were single, nine widowed and 60 were married.

\section{Pathological Stages}

The disease usually occurs first near the rectosigmoid junction (Fig. 3), though it may commence anywhere in the colon. It may remain regional throughout its entire course, but in our experience cases which are at first regional tend to become general if followed over a sufficiently long period of years. In one of our cases a regional ulcerative colitis took 15 years to involve the entire colon. If it is found that only the lower rectum is involved first, we are suspicious of the more benign condition, granular procto-colitis.

Macroscopic anatomy is best illustrated by the sigmoidoscopic and X-ray appearances described later. It is only in the very late stages of the disease when fibrosis is marked and the bowel is thin, that any marked bowel changes are to be seen when the abdomen is opened. Enlarged lymph glands, sometimes up to 2 and $3 \mathrm{~cm}$. in diameter, are often noted at operations, and are most marked in the ileo-caecal region.

The first changes seen on microscopic examination are small submucous collections of lymphocytes and eosinophil cells associated with oedema of the bowel wall. Blood vessels are often thrombosed and packed with red blood cells. Later, when ulcers are present, there is a mixture of polymorphonuclear leucocytes and lymphocytes in the submucous collections.

The surgeon is more interested in the pathology of the second or chronic stage of the disease. In this stage microscopic examination shows fibrosis, contraction and infiltration of the affected area of the bowel. It also reveals that the changes may extend much further up and down the bowel than macroscopic examination would suggest. A similar state of affairs is found in diverticulitis, where a cellulitis of the bowel wall is often found to extend well away from that part of the bowel affected by diverticuli. In two patients, one with diverticulitis and one with ulcerative colitis, where exteriorization of an infected loop had been performed as part of surgical treatment, silk stitches were placed through the bowel wall as deep as the submucosa. Suppuration about these stitches occurred within three days, but suppuration did not occur in the bowel wall of a patient who had undergone an abdominoperineal resection for carcinoma of the rectum, and in whom the excess bowel was allowed to protrude from the abdomen for four days before it was cut off.

Clinically, pathologically and from the point of view of treatment, there are, therefore, at least two distinct stages of the disease.

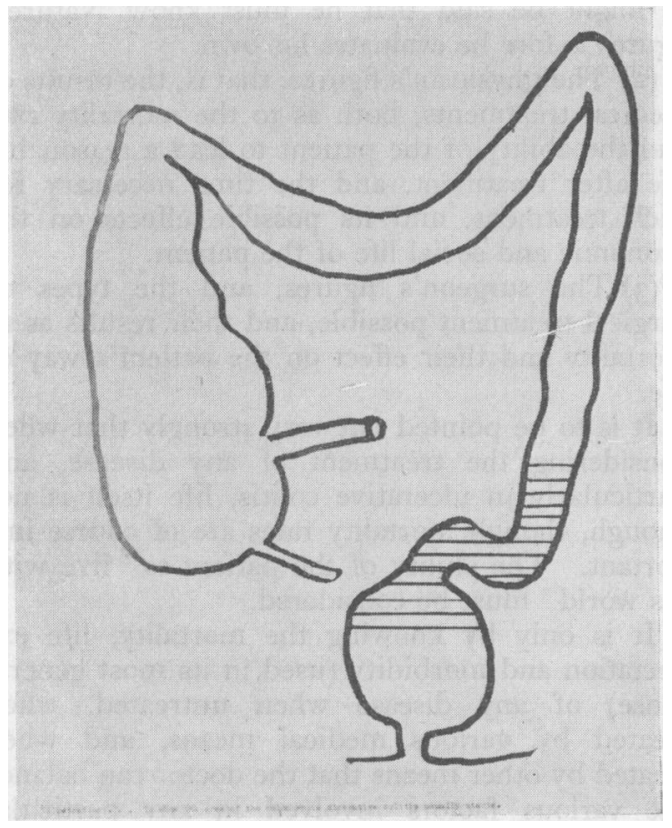

Fig. 3.-Area where disease usually commences.

In the first or acute stage there is oedema and ulceration, but little fibrosis.

In the second or chronic stage there is marked fibrosis. Mucosal regeneration has covered some or all of the granulation tissue left by the ulceration of the first stage. A thin mucous membrane has grown over the scars which, as is the case with scars anywhere in the body, have a poor blood supply. Overgrowth of the epithelium which regenerates from the edges of the ulcer may lead to polyposis; continued overgrowth to carcinoma. Thus there results an ' unstable scar,' in the sense of the term as used by plastic surgeons to describe similar scars on the skin (Fig. 4).

Exacerbations occur frequently in the course of the disease, leading to renewed attacks of ulceration and ultimately to a fibrous or 'pipestem' colon.

In the acute stage there is hope of complete cure when a medical means of combating the initiating factor of the disease has been found. In the chronic or ' mechanical' stage of ' unstable scarring' of the colon, it is probable that many patients will continue to need surgical intervention.

\section{Consideration of Treatment}

To practise his art wisely, the surgeon must know:-

(I) The course and possible complications of the untreated disease, and its mortality and morbidity. 
It might be said that he must know Nature's figures before he evaluates his own.

(z) The physician's figures, that is, the results of medical treatments, both as to the mortality rate and the ability of the patient to lead a reasonable life after treatment, and the time necessary for such treatment, and its possible effects on the economic and social life of the patient.

(3).The surgeon's figures, and the types of surgical treatment possible, and their results as to mortality and their effect on the patient's way of life.

It is to be pointed out very strongly that when considering the treatment of any disease, and particularly in ulcerative colitis, life itself is not enough, though mortality rates are of course important. The ability of the patient to "live with his world' must be considered.

It is only by knowing the mortality, life expectation and morbidity (used in its most general sense) of any disease when untreated, when treated by various medical means, and when treated by other means that the doctor can balance the various factors involved in any particular

I. Stage of multiple submucous abscesses.

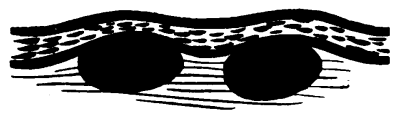

2. Stage of miliary ulcers.

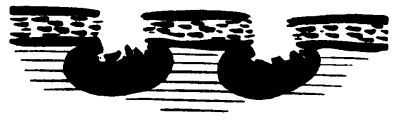

3. Small ulcers coalesce to form larger irregular ulcers.

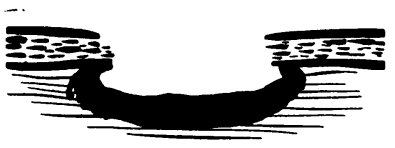

4. Base granulates and scar tissue results.

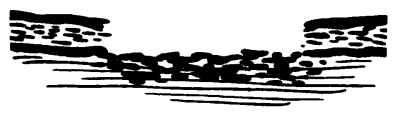

5. Regenerating mucosa grows over the granulation tissue from the edges of the ulcer. Polypi may result.

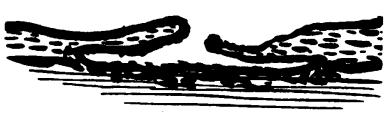

F1G. 4--Diagrammatic representation of the local course of ulcerative colitis. patient and, giving each factor its due weight, decide on the best plan for individual management.

In no disease is this balance and judgment more necessary than in chronic ulcerative colitis. In- $c$ finite patience, a knowledge of the degree of impairment of healing that has been brought about by a devastating disease, an intimate knowledge of the psychology of the patient and an accurate evaluation of his will to live are all essential in carrying out the personal, exacting and often long management of patients with chronic ulcerative colitis.

Only in a knowledge of the untreated disease do we find the sobering fact that there is quite a high rate of natural cure. Too often we are guilty of thinking of the 'patients we saved.'

\section{Course}

The disease tends to have a characteristic î periodicity, and exacerbations may occur even after a five- or ten-year period of remission. $\infty$ These spontaneous remissions may occur at any $ᄋ$ time and are, of course, attributed to the treatment being given at that particular time. It $c$ would appear, as a result of study of the cases treated at the Royal Melbourne Hospital, that the disease in most cases is either over and a so-calleg 6 'cure' produced or else the patient is dead, a $\mathbf{1}$. within a five-year period (Figs. 2 and 18 , an Table I); 78 of the 100 cases studied had had the disease for up to five years, and of these 23 died. Only two deaths occurred in the 22 cases who, when first seen, had been sick for over five years, but in the 30 patients who replied to the follow-up, there were four more deaths reported. This is in accord with the findings of Hardy and Bulmer (1944) and Kiefer (1942), who stated that the disease was less dangerous the longer the patient had had it.

It is probable that many of the patients who have had a so-called 'cure' still carry local colonic changes, since many years after an apparent cure $\delta$ a carcinoma may develop. We have noted that several of the cases with a so-called cure have 을 what amounts to an ' auto-colectomy.' At opera- $\rightarrow$ tion it was found in one such case that the ileal contents were already of the consistency of thick $\bar{N}$ tooth paste; water absorption was being done by $\sigma$ the ileum. Though this patient was having only $N$ three to five bowel actions per day, her colon had been performing only excretory and not waterabsorptive functions.

\section{Complications}

At some time during the course of the disease ${ }^{0}$ severe complications occur in about one-third of $\mathbb{\mathbb { D }}$ all cases (Fig. 5). 
Secondary anarmia is common and may result from haemorrhage, toxaemia or infection. Pollard, Block and Bachrach (1947) reported that in 109 cases of chronic ulcerative colitis 6r.5 per cent. had marked anaemia at the time of original hospital admissions. No macrocytic anaemias were noted.

Exhaustion from continually interrupted sleep and too frequent physical efforts at stool is a common and a serious complication. Many patients show also evidence of profound toxaemia.

Perforation is commonest in fulminating cases, but may occur above a stricture or after 'defunctioning' by ileostomy or colostomy.

A dramatic perforation occurred in one of our patients who was seen for the first time after perforation had occurred. She had had a transverse colostomy done previously, and whilst in hospital a cautious barium enema radiological examination was made by competent radiologists. The first abnormality noticed was that the radio-opaque bowel shadows suddenly changed from ' white' to 'black' and the in-between areas between the loops of bowel to ' light.' 'Though laparotomy was done as soon as shock permitted, the patient died ten days after the perforation from rupture of an unsuspected subphrenic abscess.

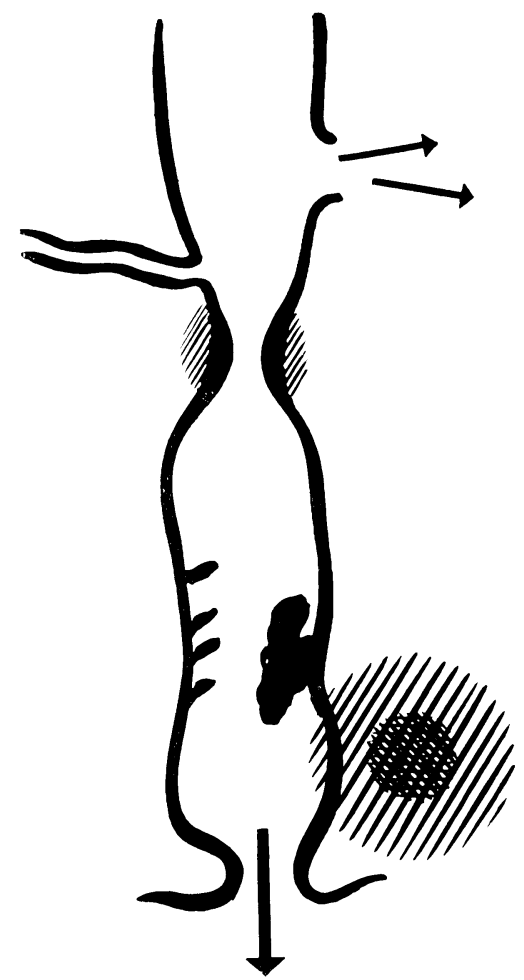

FIG, 5.-Graphic representation of the main serious local complications of ulcerative colitis.

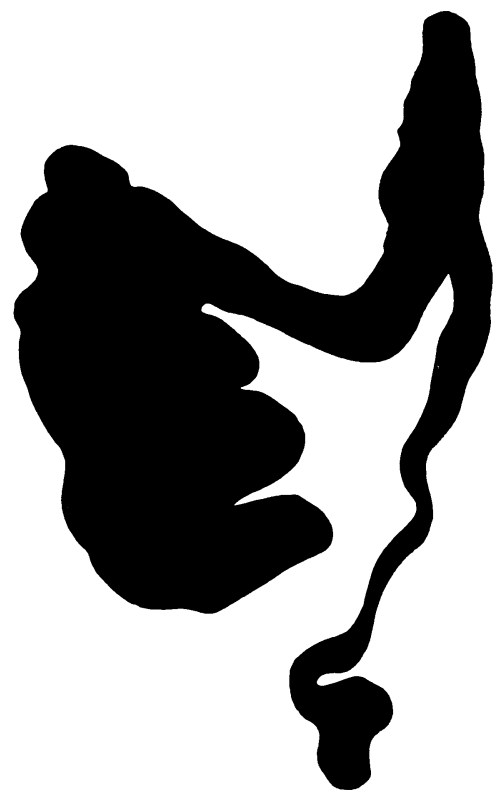

FIG. 6.- To illustrate typical X-ray appearance of a late chronic ulcerative colitis in which there has been loss of haustration, narrowing and shortening of the colon from the rectum to the right hand side of the transverse colon.

Fistulae occurred more frequently in this series than was expected from overseas statistics, 4 of 24 patients operated upon having fistulae. 'The commonest fistulae are to the skin. In two of our cases the fistulae were to the abdominal skin; one followed removal of the appendix and the other drainage of an abscess after rupture of what was then thought to be a ruptured diverticulum. One case had multiple fistulae in the perineum. Fistulae also occurred to the bladder, the ragina and other parts of the bowel.

Perirectal inflammation, though probably present in many cases in which the rectum is involved, was very marked in one of our cases. Oedema of the vulva and the labia minora resulted in enlargement so marked that walking caused intolerable discomfort. The local doctor in a country town had removed one labium. After removal of the rectum the oedema of the vulva subsided, and correction of the perineal asymetry was carried out.

Stricture was more common in the rectum and other parts of the bowel when a defunctioning procedure of some sort had been done. 'Two of the 24 operation cases had marked rectal stricture (Fig. I7). Bargen (I943) reported 22 per cent. of strictures in 36 patients who required operations for $5^{1}$ complications. Monaghan (1944) found stricture more common where the bowel was not 


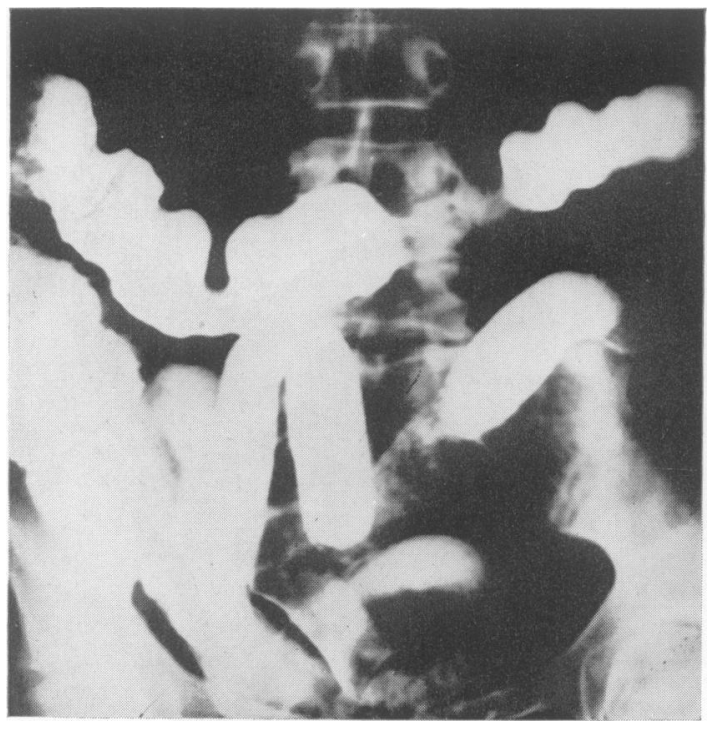

FIG. 7.-Radiograph of a barium enema in a patient aged 42 years who had had ulcerative colitis for 12 years. There is loss of haustration and obvious rigidity and stiffening of the descending and sigmoid colon.

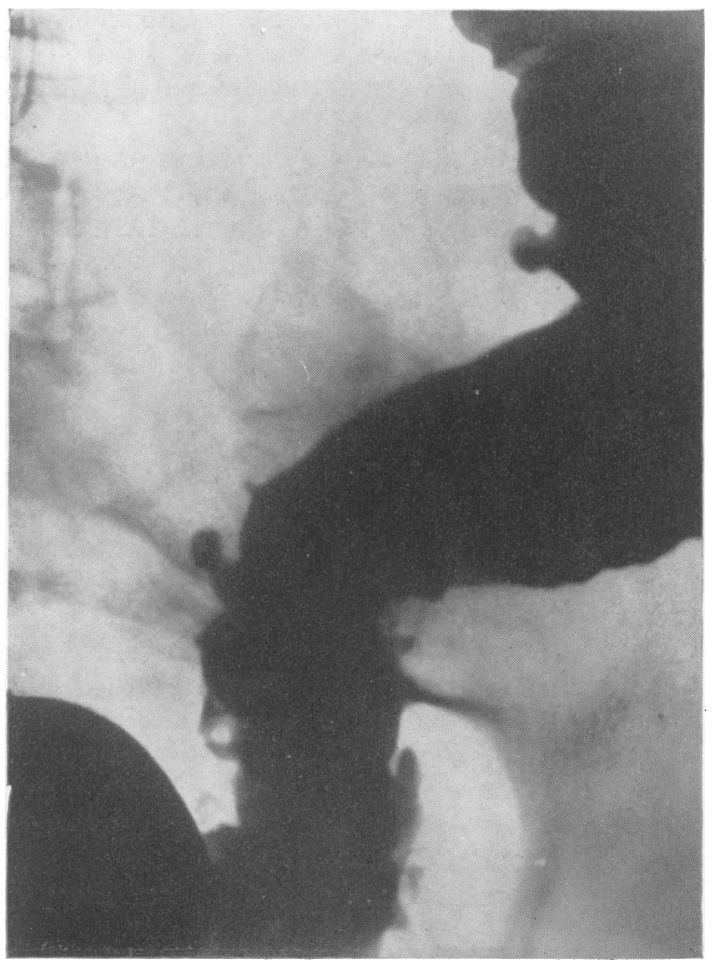

FIG. 9.-Suggests that diverticuli are present.

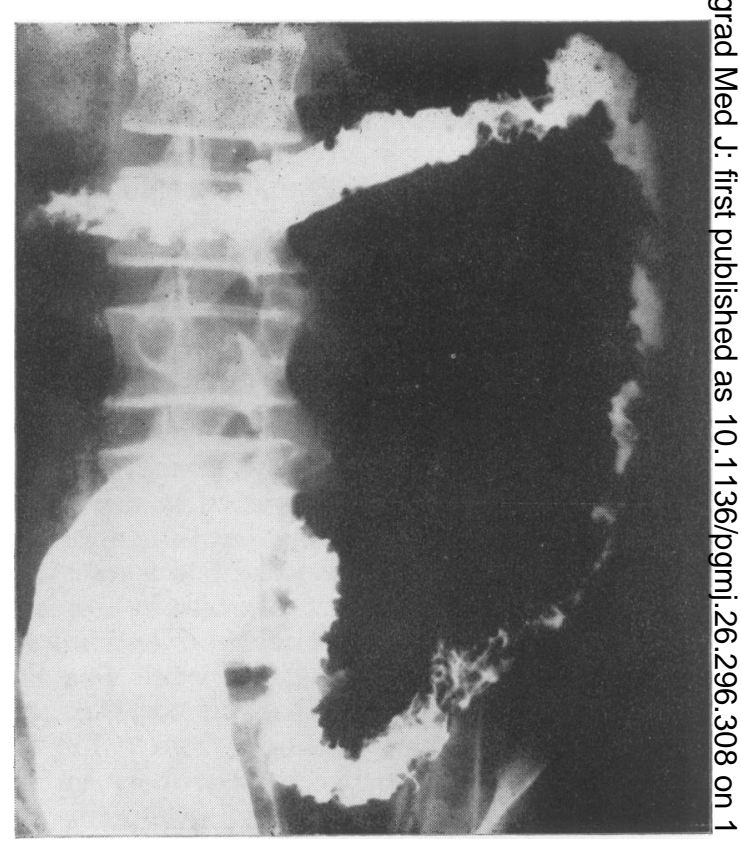

FIG. 8.-Barium enema X-ray examination of a man, aged 32 years, who a year before had had a bowel ${ }^{\Phi}$ perforation and general peritonitis. He recoversd $\vec{c}$ following drainage of the area of perforation afdo 'defunctioning' transverse colostomy, but con-. tinued to have a draining abdominal sinus and creasing frequency of defaecation and diarrhoe At operation for resection of the affected bowel no polypi and no diverticuli could be found on meticulous examination, and the pathologist reported that microscopy of sections of the excised ${ }_{\odot}^{\Phi}$ bowel showed only ty $\rho$ ical appearances of ulcerative colitis. Shows the ragged appearance of the bowelo믐 with the suggestion of polypi.

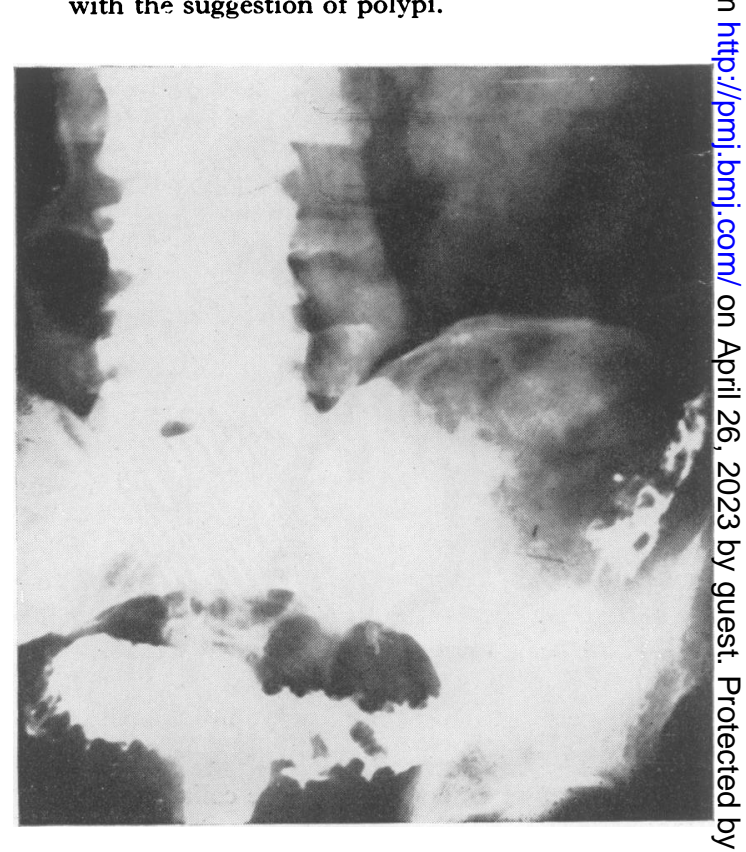

FIg. 10.-From the same patient, suggests that there are polypi. 
' in circuit.' He reported that stricture occurred in about ro per cent. of all cases.

Polyposis occurs in approximately one-tenth of cases in reported series, and occurred in two of our 24 operation cases. The polyposis is an irregular overgrowth of regenerating epithelium from the edges of the howel ulcers.

Carcinoma probably follows the overgrowth of mucosa found during the repair phase. It is variously given as occurring in from two to four per cent. of cases. It seems that the longer the patient has had the disease the more likely is the development of a carcinoma. In our series of 24 operation cases there were two in which, at the time of operation, a carcinoma was present.

Cattell and Boehme (1946) have pointed out that apparent cure or remission, even though it may have lasted for many years, is no insurance against the development of malignancy. Cave (1946), reporting the late results in surgery of ulcerative colitis, mentions that in three of ror cases a carcinoma was present, and these had all developed on polypi. Monaghan (1944) found I.5 per cent. of carcinomata in cases of ulcerative colitis; Streicher (1947), I.2 per cent.; and Bargen, Jackman and Carr, 3.2 per cent.

Miscellaneous. Besides the complications already mentioned, three of our 24 patients complained of joint pains and joint stiffness which disappeared following operation. In a boy of 19 the pains were so severe as to prevent him getting out of bed.

Spontaneous thrombephlebitis of the deep veins of the leg was present in two patients. One patient had severe iritis which subsided under treatment only after removal of the colon at the second stage of sub-total colectomy.

Frequent mention has been made in recent literature of poor hepatic function which is found in many of these patients. This may be secondary to dietetic disturbances, or to the toxaemia of severe illness.

Pollard (1945) noted poor hepatic function, as shown by liver function tests, in patients with ulcerative colitis.

A discussion of possible relationship between cirrhosis of the liver and ulcerative colitis is given in an editorial in the British Medical Fournal (1949).

The disease often produces profound cachexia and hypoproteinaemia, which is of importance to the surgeon. This is probably in the main a result of excessive loss of protein by the bowel, sometimes as much as $35 \mathrm{gm}$. a day, and from general and local infection. Patients tend to eat less than they should as they soon learn that every time they eat their bowels will act.

We have found that there are considerable alterations in the salt metabolism, making it very difficult to maintain an adequate salt intake without at the same time increasing the number of bowel actions a day. Sodium chloride lack may account for the listlessness, lack of interest and nausea often seen in the very sick patient.

Many patients look much younger than their years, and in particular young adults may lack full sexual maturity. Following removal of the major part of the diseased bowel, they may be seen to change within a few months from an infantile appearance to an appearance and development of hair, breasts, external genitalia, etc., consistent with their age. A boy of I9 had to shave once a month before sub-total colectomy was performed. Within two months of this operation he had to shave at least three times a week.

\section{Symptoms, Signs and Diagnosis}

In most instances it is the bowel symptoms that bring the patient to the doctor, medical advice being sought because of persistent diarrhoea and the passage of blood and mucus in the stools. This is particularly suggestive of ulcerative colitis in patients between 20 and 40 years of age who have not been outside their own country. The disease can, however, occur at any age and I I of our 100 cases were under 20 or over 60 years of age.

Sigmoidoscopic examination and radiological examination with a barium enema are essential for diagnosis, and help to determine the stage of the disease and the presence of complications.

It is essential to exclude specific dysenteries both by the history and by an examination of the stools for organisms and amoebi and culture for the specific dysentery bacilli. Sigmoidoscopic examination helps to exclude the colitis of the specific dysenteries.

Sigmoidoscopic examination confirms the diagnosis in 85 per cent. of cases examined (Fig. $\mathrm{I}$ I).

While some patients can be satisfactorily examined in the left lateral or Sim's position, it is better to make use of gravity and to perform this examination with the patient sloping so that the head is the lowest part of the body-Buie's position. This may be done by having the patient lie in a cross-bed position on his face with the hips still on the bed and the chest and head resting on a pillow or stools on the floor, at a lower level than the pelvis (Fig. 12). If an operating or examining table is available, tilting is more readily performed. A somewhat similar, but not so effective, result can be obtained by the kneechest position in males. The author has yet to see a patient who could not be satisfactorily examined, no matter how frequent the stools.

No particular pre-examination preparation is performed except that patients are asked to fast for three hours beforehand and to open the bowels before being examined. A 'Coldlite' sig- 


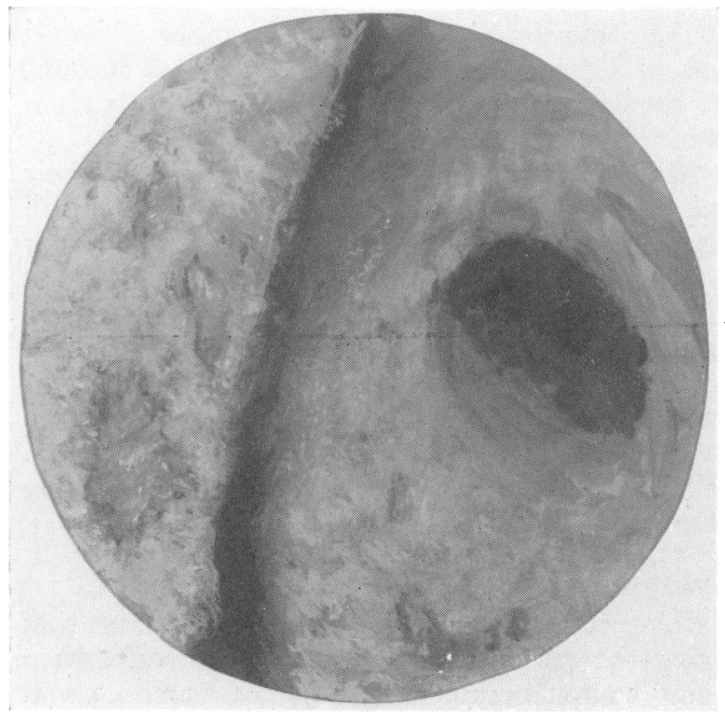

FIG. II.-A drawing of the bowel in a late part of the first stage as seen through a sigmoidoscope. The bowel has to be inflated; there are irregular shallow grey ulcers of various sizes; there is a granulomatous swollen, fiery red and oedematous mucosa, and flecks of pus and blood are seen, both on the bowel wall (which bleeds very readily on trauma during passage of the instrument), and on and mixed with thin faeces. In the second stage the bowel wall is much more white and opaque in appearance, and the rectum is so stiff that it stands dilated and does not have to be inflated. well as the stomach 'blushes' in states of anxiety lying fibrosis. Considerable stiffness of the bowel walls is noticeable while the sigmoidoscope is being advanced.

During exacerbations of the disease there are large, irregular grey ulcers superimposed on the white scars of previous attacks, and bleeding areas stand out in contrast with the whiter, more opaque and stiff bowel wall.

The barium enema examination in the first or acute stage often shows no changes. The ulcers may show up only when double-contrast, or air plus barium methods are used.

In the second stage of the disease there is a lack of haustration of the part of the colon involved. This alone is not enough for positive diagnosis, as lack of haustration may occur in other conditions. Associated with shortening and narrowing of the colon, particularly in the presence of polypi as seen in post-evacuation films or with double contrast methods, however, it is almost diagnostic. Occasionally a barium enema is the only way of confirming a clinical diagnosis, particularly if (as was present in one of our cases) the disease is localized to regions above the sigmoid colon (Figs. 6, 7, 8, 9 and 10). Carcinoma in a bowel which is the seat of ulcerative colitio of appears on radiological examination as a filling. defect in the rigid tube of affected bowel. Polyps are often demonstrable. Carcinoma is, however, often found only at operation.

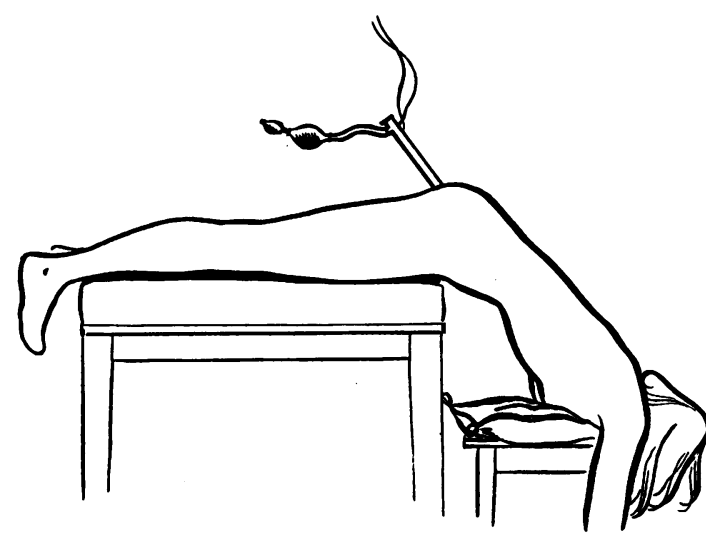

FIG. 12.-To show Buie's position for sigmoidoscopy. This position is particularly useful in examining patients who have liquid motions, as in ulcerative colitis. In this case the patient is leaning over the side of a bed and resting her chest on a small stool covered by a cushion. When available, it is more convenient to use the 'break' in an operating table and hang the patient over the acute angle of the table with the thorax sloping as far as possible downwards. 
Differential Diagnosis, or the Indirect Importance of Chronic Ulcerative Colitis to the Surgeon

The importance of chronic ulcerative colitis in differential diagnosis is illustrated by the fact that even in our short personal series of 24 cases operated on, two had had haemorrhoidectomy before being seen (one had a rectal stricture as a result of this), and in three others the appendix had been removed soon after the onset of the disease. In only one of these was the appendix shown to be inflamed by microscopic examination.

It must be remembered that a case of ulcerative colitis may present as an ' acute abdomen.' There may be a rapid onset of local infective signs and symptoms as the result of pericolic infection, or of perforation with local or general peritonitis.

A history of recurrent attacks of diarrhoea or the passage of blood or mucus per rectum may be of aid, whilst sigmoidoscopic examination should clinch the diagnosis in 85 per cent. of cases.

Local signs of abdominal infection may be confused with those of acute appendicitis. Often the appendix is truly involved with the remainder of the colon, but at operation it is surprising how inflamed the appendix can appear without having caused symptoms or signs of acute appendicitis.

Left-sided signs with bowel symptoms may suggest diverticulitis and its complications. Whereas diverticulitis is rare before the age of 45 , ulcerative colitis is rare after that age.

Among the many other acute conditions with which ulcerative colitis may be confused, perforated ulcer, acute cholecystitis and gynaecological conditions may be mentioned.

Tuberculous enteritis is rare outside sanatoria and should not be diagnosed except in the presence of active tuberculosis elsewhere in the body. One case seen by the author progressed from first symptom to death within eight weeks, despite massive doses of streptomycin. There had been a mistaken impression that the patient was suffering from tuberculous enteritis, though chest X-rays and sputum examinations were repeatedly negative. He had been treated many years previously in a sanatorium for tuberculosis of the chest, but this had healed without X-ray trace.

Ulcerative colitis may present with the passage of blood by the rectum and simulate bleeding haemorrhoids. Passage of blood by the rectum is most often due to bleeding haemorrhoids, but carcinoma and ulcerative colitis should not be forgotten and should not be missed if a sigmoidoscopic examination has been made. If, on sigmoidoscopic examination of a patient suspected of having simple haemorrhoids the faeces are bloodstained as high as the sigmoid colon, a barium enema examination should be done to exclude ulcerative colitis at a higher level.

Patients who complain of rectal pain and the passage of blood and perhaps yellowish mucus per rectum are found occasionally to have granular procto-colitis. This disease occurs in the same age group. On sigmoidoscopic examination there is a granular appearance of the lower part of the rectum, and plaques of pus on the surface of the reddened, oedematous bowel may resemble ulcers.

Patients who take routine doses of hypertonic salts also may present a granular reddened appearance of the lower part of the large bowel-an appearance which disappears as soon as the taking of salts as an aperient has been stopped.

\section{Mortality Rate when Untreated}

An approximation to the mortality for the disease untreated can be obtained from results published in years gone by. From these it appears that from 40 to 50 per cent. of the patients would die.

\section{Medical Treatment and the Results}

In the absence, so far, of a specific remedy, medical treatment aims at tiding the patient over until the 'body beats the disease.' Supportive treatment and therapy with antibiotics against secondary invaders has greatly improved in the last few years, and while the mortality both here and abroad in all cases is still about 20 per cent., with the controlled administration of blood, serum, sulphathalidine, penicillin and streptomycin, and perhaps the more frequent use of the "medical ileostomy' afforded by an indwelling doublelumen Miller-Abbott tube, this mortality rate should fall. This would mean an overall increase in the length of survival, because the mortality rate for each attack decreases with the length of time that the patient has suffered from the disease.

Personal experience and overseas reports suggest that though medical treatment may aid in terminating a particular exacerbation and so help to save the patient's life, it rarely cures the disease or prevents further attacks and complications.

Duffy (personal communication, 1946) found that of 71 patients treated medically at the Alfred Hospital over a 17-year period, 36 per cent. died.

Among 34I patients who attended the three main public hospitals in Melbourne over a tenyear period ending in 1945,87 or 25 per cent. died under medical treatment $(23$ were treated surgically).

Hardy and Bulmer (1944) point out that the mortality in the first year of the disease is 75 per cent.; 33 per cent. in the second year and 17 per cent. in the third year. 
Kiefer (1946) reported 63.6 per cent. of cases with severe toxaemia and a raised temperature who had a poor result from treatment. When there were mainly local manifestations, 78 per cent. of cases he could report had a good result. For the well-established disease there was no specific cure short of removal of the entire colon and rectum.

Bargen (1943) reported that 44 patients in $87 \mathrm{I}$ consecutive cases of ulcerative colitis had a complete recovery after treatment.

While medical measures may not bring about complete cure, nevertheless they enable a great number of patients to 'live with their disease' in reasonable comfort, often for many years. Many are able to carry on their usual work. When the disease is well established, however, it would seem that sooner or later slow local progress or the onset of complications tends to bring the sufferer back to medical care.

Comprehensive records of cases seen by my father over a period of 20 .years or more suggests that seldom if ever is the bowel completely returned to normal by medical means. One of his cases had a remission for over ten years, and two others developed strictures 14 and ${ }_{5} 5$ years after apparent cure.

It is to medical treatment that we must look for improvement in both the mortality rates and rehabilitation. Particularly is it to be hoped that early treatment in the acute stage will prevent patients entering the chronic 'unstable scar' stage with its irreversible changes. It is probable that surgery will always play a part in the treatment of this second chronic and fibrotic stage.

\section{Indications for Surgical Intervention}

In most of our cases the indication for surgical treatment has been impending death or failure of prolonged and efficient medical treatment. These are no longer satisfactory indications. It must be emphasized that life is not everything, and that life with up to 15 stools a day may be quite intolerable. Many patients, though not in immediate danger of death, are complete invalids and are entirely unfit for work. We feel that we have taken too conservative a view in regard to operation.

The risk of the operation must be weighed against the risk of death without operation; the gravity of complications present or threatened must be considered, the ability of the patient to lead a reasonable life enquired into, and the wishes of the patient, after he has had a talk with other patients who have been operated on, taken into account.

In the 24 cases personally operated on, and in the 23 treated surgically at the Royal Melbourne Hospital between 1937 and 1942, the mortality has been the same with surgical as with medical treatment (between 20 and 25 per cent.). The final condition of the patient should therefore be the determining factor in the broad choice of policy as to treatment.

If it is a choice between medical treatment and surgical treatment by ileostomy, it cannot be doubted that the patient is better off with medical treatment, unless an ileostomy is essential to life.

The end results of a successful sub-total colectomy with an ileo-rectal anastomosis by the spur method have been so satisfactory and have compared so favourably with the end results of medical treatment that we now prefer it to medical treatment in 'borderline' cases. Patients who have had this operation have been able to go back to work, to get married, to have children and to live normal lives. One girl of 19 who had had the operation of sub-total colectomy and ileo-rectal anastomosis was recently married. Her bridesmaid also had no colon (an acolonic wedding).

If patients have had a long period of symptoms and can live with their disease without systemic manifestations, they should have at least five to eight bowel motions in every 24 hours before the operation of ileo-rectal anastomosis is considered. Otherwise the indications for operation are the presence of complications.

\section{When Should Surgery be Undertaken ?}

All five deaths in our 24 operation cases have? been in the first ileostomy stage for fulminating cases (representing a mortality of 66 per cent. for this operation), and though every surgeon seems to remember when an ileostomy has been lifesaving, a study of the very high mortality of ileostomy when done during an acute exacerbation puts one in agreement with those who feel that surgery is best done after the physician, with his greatly improved supportive and antibiotic measures, has helped to tide the patient over the particular exacerbation.

Monaghan (1944) (95 per cent.) found a big fall in mortality when ileostomy for the acute phase was dropped.

In 34I cases in Melbourne public hospitals over ten years, five of the six ileostomies reported ended fatally.

It is the common finding that the disease continues locally in the defunctioned colon and frequently a further deterioration in the patient's general condition occurs between four and six months after an ileostomy. Thus although systemic manifestations of toxicity are lessened dramatic relief for the patient is not always to be expected. The upset in water and salt circulation consequent upon an ileostomy may tip the balance against a desperately sick patient and prove fatal. Modern medical treatment has greatly improved 


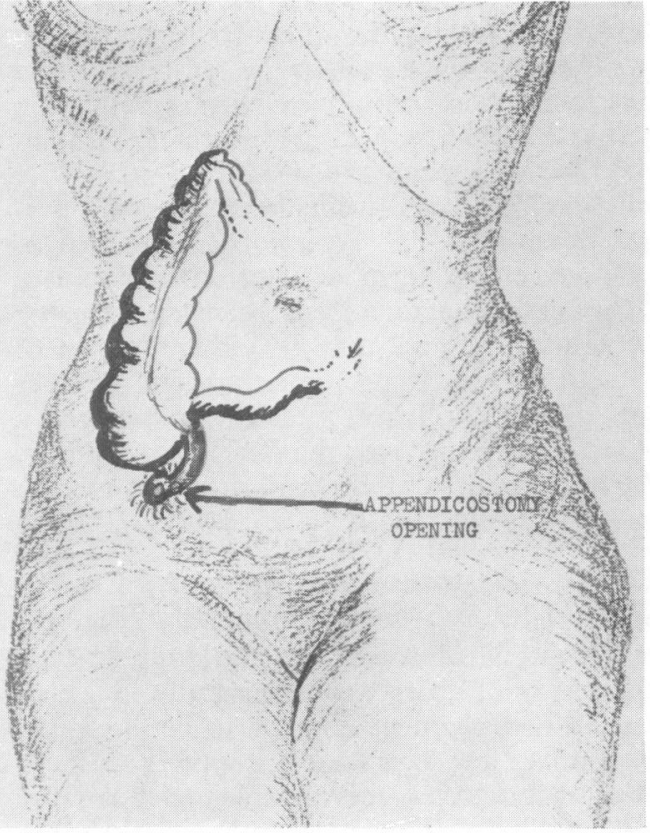

(a)

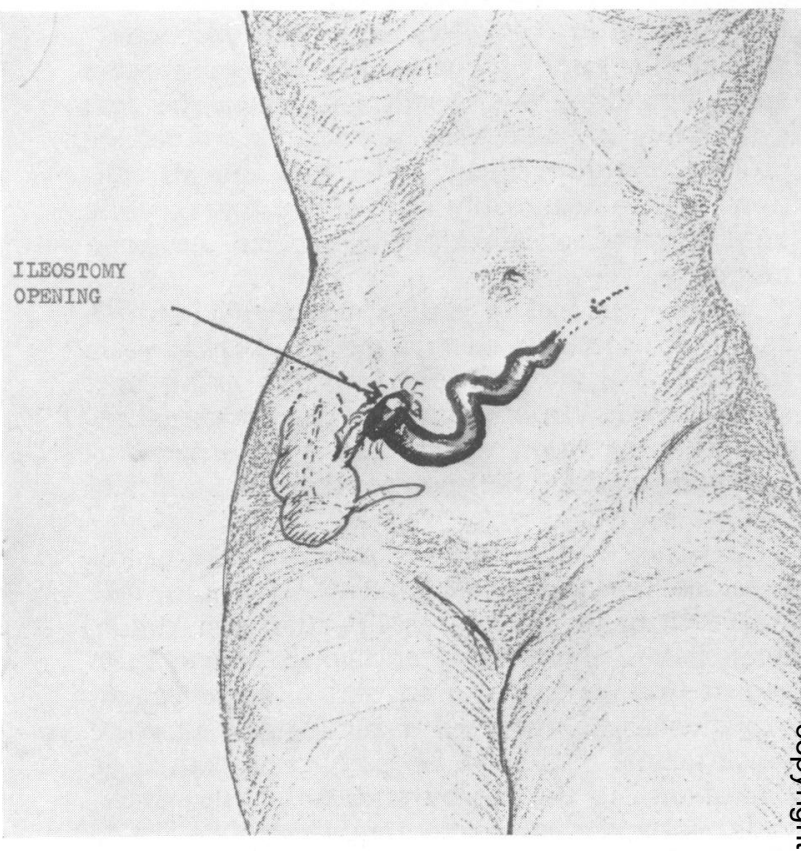

(b)

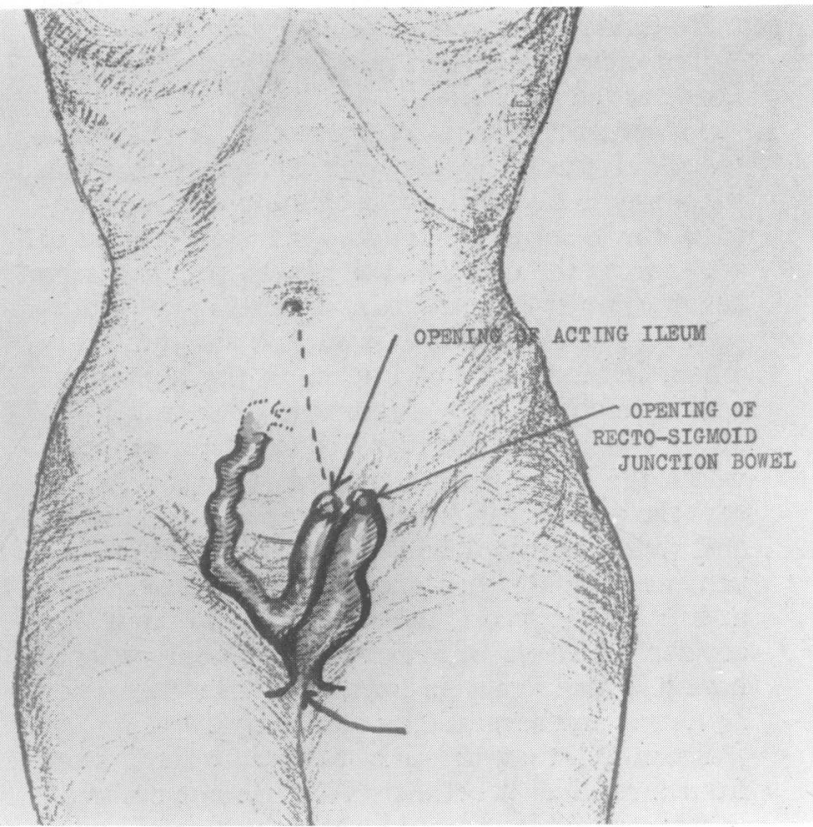

FIG. I3.-Operations in use in the treatment of ulcera tive colitis. (a) Appendicostomy. (b) Ileostomye (c) Ileo-rectal anastomosis by a spur and clamp method.

(c) 
the outlook in acute exacarbations, so that surgery may more safely await the expected remission.

\section{Surgical Procedures (Fig. I 3 a, b and c)}

Appendicostomy, though now considered by most surgeons to be outmoded, has been very helpful in two patients in our series who were desperately sick at the time of operation. In one woman appendicostomy was performed when she was desperately ill, and was followed by immediate prolonged improvement. She was able to continue with a reasonably normal life for 15 years until a rectal stricture made further operation necessary.

Another girl had I $_{5}$ years of reasonable life with an appendicostomy, and during 13 of those years she was able to work and earn her living as a stenographer. In both of these cases eventual removal of the colon was necessary because complications disabled the patients both economically and socially.

Because of such cases it may be wise to reconsider the status of appendicostomy in the treatment of very acute cases of ulcerative colitis. Even before the days of antibiotics it had been shown that appendicostomy was often of benefit to patients who appeared to be dying of an acute exacerbation. It could be performed with little disturbance to the patient and, unlike ileostomy, it did not add a grave water and electrolyte loss to the burdens of an already dehydrated and toxic patient. Appendicostomy and the continuous drip installation of streptomycin solution and sulphathalidine emulsions would appear to offer hope in desperate cases.

Ileostomy is at present the most commonly used procedure.

Many patients are young, good looking and unmarried, and all are terrified at the thought of a permanent ileostomy. They will not get married if they have an ileostomy, though if they are already married they may tolerate it with little upset in their marital state.

Therefore the decision to perform an ileostomy, which must almost certainly be permanent, is a very serious one and should be made only when no other procedure can take its place. An ileostomy may be the price the patient has to pay for life.

In the management of temporary or permanent ileostomies there are two possible approaches to the problem of preventing skin excoriation.

Firstly, substances may be given by mouth to thicken the ileal discharge. The administration of frequent doses of agar, either as granules eaten from a spoon with a little flavouring cordial added, or as a thick jelly, has been found most helpful. This was suggested by Professor R. D. Wright, and its action is ascribed to imbibition.
Secondly, local applications may be made to the skin surrounding the site of the ileostomy. Many substances have been suggested but the two we have found most useful have been egg albumen (suggested by Professor F. M. Burnett) and industrial ' barrier cream.'

Many appliances are available for use with permanent ileostomies. A typical bag is shown in Fig. I6. A cheap form of ileostomy apparatus with disposable containers can be made by using male condoms. These may be either tied on or stuck with 'Dermatone' quick-drying rubber cement to an appliance which incorporates a safety outer covering over the ileostomy opening. The male condom stretches and does not require too frequent disposal.

\section{Ileo-Rectal Anastomosis by Spur and Clamp, Followed by Sub-Total Colectomy (Fig. I4)}

The operation advocated by Sir Hugh Devine ( 1945 ) consists of a first stage ileostomy in which the opened ileal segment is made to lie alongside the rectum. A few days later the spur is crushed. After this operation patients are able to get married and have children. They have no bowel discharge on to their abdomen and life to them is more than just tolerable.

Many months later, when the patient has put on two or three stone in weight, the second stage of the operation is performed-removal of the diseased colon. Patients tolerate this seemingly formidable resection well, and it often takes under three-quarters of an hour of operating time.

Objections have been raised against joining the ileum to the rectum:-

Firstly, that there is too great a discomfort from too fluid stools. It is well known that if an ileostomy is done with the opening on the abdomen, the lower ileum takes over the absorption of water from the colon and the ileostomy discharge becomes putty-like or of the consistency of toothpaste. The ileum behaves in just the same way when, instead of emptying on to the abdominal wall it empties into a remnant of rectum. In other words, all that is asked of the rectum to which the ileum is anastomosed is a sphincter, so that the patient can hold the already concentrated and water-extracted bowel contents till it is convenient to defaecate. This is preferable to having a bag hanging on the abdomen in wait for accidents. In point of fact, most of our patients have less than five semi-formed bowel motions per 24 hours, and several only one or two.

Secondly, that there is too great discomfort from a residual proctitis. This has not occurred in our series. If it should occur the area of bowel remaining is so small that there should be no systemic manifestations from it, and with the 

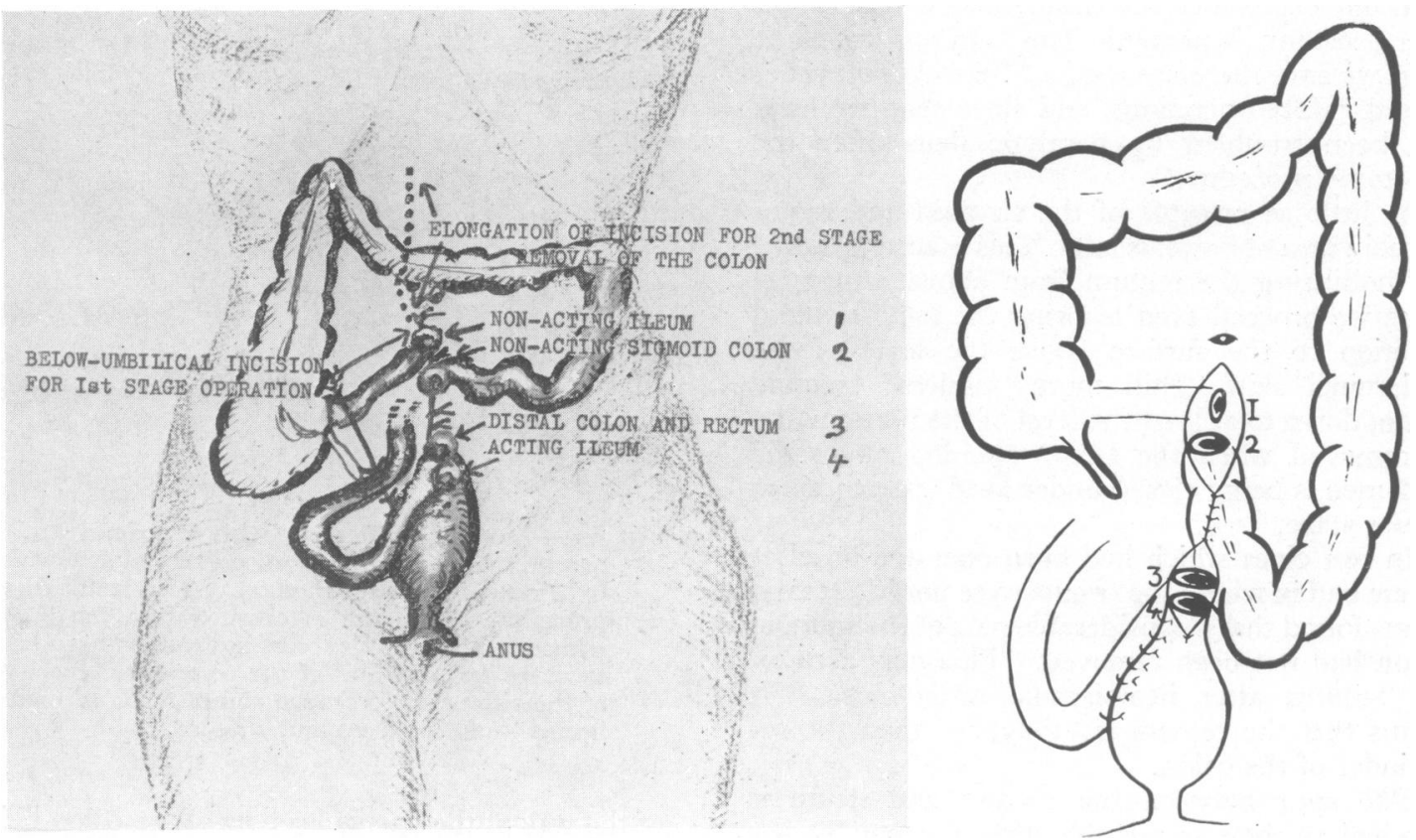

FI's. 14. - To show the arrangement of the four intestinal openings on the abdomen after the first stage of a sub-total colectomy as described.

passage of time should come the natural cessation of exacerbations. Unless the rectum is removed with the colon, proctitis with the passage of pus and blood continues to annoy the patient. We have found, however (as reported also by Monaghan, 1944) that this proctitis tends to clear up with the passage of ileal contents through the rectum. It did not clear up where the rectum was left as an isolated pouch, as in two of our early cases. Removal of the rectum was necessary. Even if a few patients were to have occasional proctitis they would surely prefer this than to have the much-dreaded ileostomy all the time.

Thirdly, it has been said that joining the ileum to the rectum adds to the operation hazard. Our experience does not support this. At the first operation an ileostomy is performed; the only difference in the procedure is that the opening is put alongside the transected recto-sigmoid and held to the rectum with a few loose silk sutures which pass only through the peritoneum to make a spur. The procedure is simple and can be quickly performed.

In two cases where there had already been operations on the rectum, we found a sub-total colectomy with retention of a little of the proximal end of the colon to be a satisfactory procedure. A small amount of caecum and ascending colon was left to act as a reservoir and water-absorption area, and the remaining colon and rectum was removed later. One of the two patients who have had this procedure has a bowel motion twice a week, and the other every third day.

In other words, a little colon is better than none -and either end of the colon can with advantage be retained.

Points in the operative technique of sub-total colectomy and ileo-rectal anastomosis. Our combined experience with 24 patients who have had a sub-total colectomy performed has taught us some technical lessons that may be of help to others. Five patients died in the first or ileostomy stage, and in four of these who were in acute exacerbations ileostomy was attempted when all else had failed to stay the steady and rapid approach of death. It is doubtful whether it was good judgment to operate on these last-mentioned cases.

It is the ileostomy or first stage of the procedure which is dangerous. Preparation for this should therefore be as thorough and complete as the patient's condition will allow. It should include transfusions of blood, protein and sodium chloride as necessary. Penicillin and sulphathalidine (I $\frac{1}{2}$ gm. by mouth every four hours) are helpful in producing a temporary remission of the disease. Vitamin $\mathrm{K}$ is given to prevent increased loss of blood while sulphathalidine is being exhibited. 
In our experience the commonest complication after ileostomy is paralytic ileus. In our last eight cases we have therefore used a Miller-Abbott tube, passed before operations, and since then we have not been troubled by paralytic ileus after the ileostomy procedure.

As little as possible of the sigmoid and rectosigmoid area of bowel is left. This is accomplished by mobilizing the rectum from above. In most cases we proceed even to bring the recto-sigmoid junction to the surface above the level of the abdominal skin. Still more 'useless' sigmoid colon, down to at least the level of the peritoneum, is removed when the bowel opening on to the abdomen is being closed under local anaesthesia at a later stage.

In two cases which had been operated on elsewhere and in whom the results were unsatisfactory, it was found that a considerable part of the sigmoid colon had not been removed. This may account for failures after ileo-sigmoid anastomosis. It seems that the rectum is 'tougher' than the remainder of the colon.

The spur between the rectum and ileum is crushed as soon as possible after the patient has had a satisfactory ileostomy motion. This minimizes the post-operative upset of water balance caused by an ileostomy by helping water absorption at an early stage. It is also preferred by the patient who, within a few days of operation, has most of the ileostomy discharge passing per rectum.

Even if a rectal stricture is present it is still possible to perform an ileo-rectal anastomosis by the clamp method. In two cases (Devine, J., 1947) the rectum was mobilized from above and the crushing clamp passed through the stricture. By this means the resultant alimentary passage at the point of stricture had half of its circumference formed by normal, dilatable ileum (Fig. I 5 ).

Between the stages the 'defunctioned' colon becomes smaller in calibre and lessened in blood supply, and the general health, weight and healing powers of the patients improve markedly.

The second stage of resection of the 'defunctioned ' colon becomes a well-tolerated procedure if attention is paid to the following technical points :-

Three days before the operation a MillerAbbott tube is passed and the small bowel evacuated. At operation it takes up little space in the abdomen and is a small 'pocket handkerchief' of deflated loops which do not get in the surgeon's way. The whole of the operation is then done under full vision.

Full use is made of suitable alterations in the tilt of the operating table at various stages of the operation. Gravity drops the small intestine out

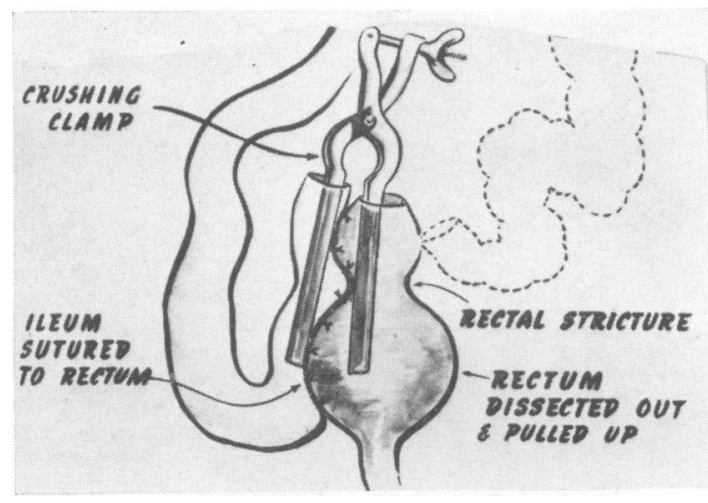

FIG. I 5.-Method of dealing with a stricture of the rectum while performing an ileo-rectal anastomosis by a crushing clamp method. As a result of this procedure the ileum is crushed into the rectum with one blade of the crushing clamp through the stricture and one-half of the composite bowel wall at the site of the stricture comes to be formed by normal unfibrosed muscular ileum.

of the way of the particular part of the colon being removed. As an example, the table is tilted down on the right side when the descending colon is being freed. The abdominal wall can be lifted of the intestine with a Devine abdominal retractor so that the hepatic and splenic flexures are easif accessible and are dissected under full vision without undue handling of the small intestines.

There is no necessity to remove the regional lymph nodes as the disease is not malignant, and there is less shock to the patient if the least possible number of sympathetic nerves are cut. Therefore when dividing the mesocolon the operator keeps as close to the bowel wall as possible, thereby minimizing shock.

It has been found quickest and easiest if the 'defunctioned' abdominal fistulae are dissected out of the abdominal wall first, and the colon is then removed from both ends at once. Lateral paracolic gutter incisions on both sides enable mobilization of the colon medially towards its midline vascular axis. The colon on either side of the hepatic and splenic flexures is controlled early, so that the flexures are pulled down and more easily dissected under tension. Silk is used for all ties inside the abdomen and continuous sutures of catgut are used to reperitonize all raw areas. Tubes are placed in both flanks.

\section{Should the Diseased Colon be Excised ?}

Whatever the initial operation we advocate that the bowel should be removed at a later operation because:- 


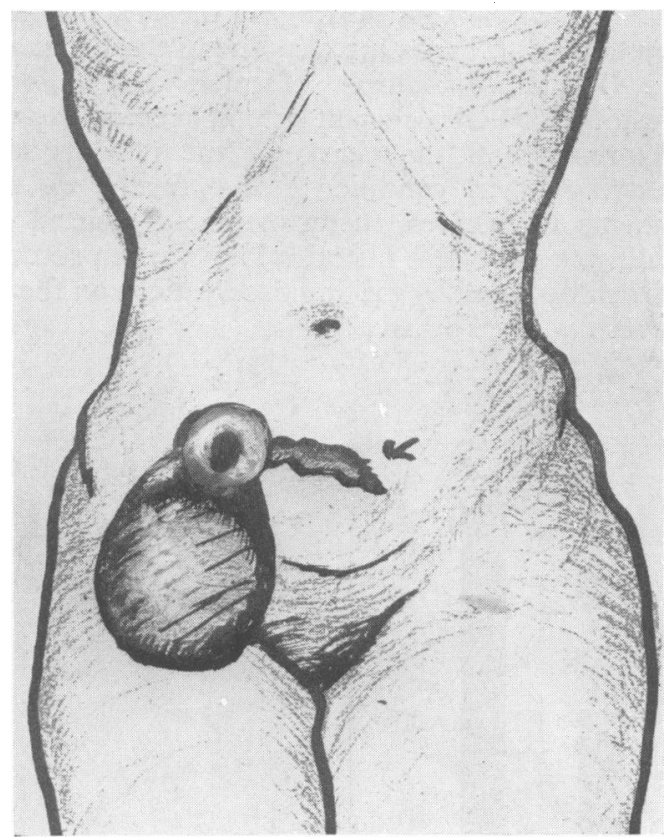

FIG. 16.- Showing one type of ileostomy bag in use over the opening of an ileostomy in the right iliac fossa.

After sub-total colectomy with ileo-rectal anastomosis the patient is left with no abdominal fistulae, acting or otherwise.

Joint pains, boils and lack of perfect health usually continue until the bowel 'cesspit' has been removed, though there are some exceptions to this. Much blood and pus may continue to be discharged per rectum, whilst after an initial improvement in the general condition lasting some months a regression often occurs.

As the disease still continues in the "defunctioned ' colon, it is subject to all the complications which may occur in untreated ulcerative colitis, i.e., 4 per cent. or more may develop a carcinoma, perforation is not uncommon and there may be stricture, marked blood loss, toxicity, joint pains, etc. Whenever the bowel empties its blood and pus its movements reflexly stimulate the rectum and help to increase small and large bowel motility and thus increase the frequency of defaecation (Devine, J., 1946).

In some cases full water absorption by the ileum does not occur until the 'defunctioned' colon has been removed, as also reported by Cave (1946).

The objection usually advanced against removing the diseased bowel is that too great a risk is involved. None of our patients, however, died as the result of the colectomy, all our fatalities occurring after the first or ileostomy stage. The present series therefore does not support this objection.

\section{Vagotomy}

It has been reported (Dennis and Eddy, I947; Dennis et al., I948; Thorek, 1948) that vagotomy was of benefit to a percentage of early cases of ulcerative colitis where local bowel changes were not very marked. As yet the results are unconfirmed. It must not be forgotten, however, that there are well-known unpleasant sequelae to any vagotomy, which include gastric retention with foul eructations, dumping syndrome, etc.

The place of vagotomy in the treatment of early cases of ulcerative colitis is yet to be determined.

\section{Conclusion}

Idiopathic ulcerative colitis is a cruel but important disease which kills a high percentage of its victims and renders a large number of the survivors invalids for life, under a constant threat of dread complications. It attacks its victims in the prime of life. It has an acute phase of which we do not as yet know the aetiology. It has a chronic phase characterized by secondary infections and fibrosis. The treatment of the first phase is primarily medical; the treatment of the second

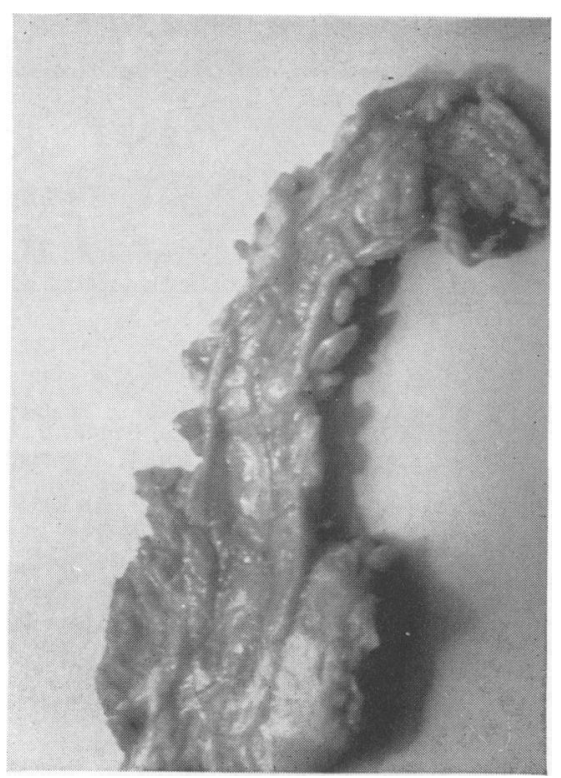

FIG. 17.- Photograph of a stricture and marked perirectal fibrosis in the colon and rectum of a girl of 26 years who had had ulcerative colitis over a period of six years. 
phase may be surgical. Patience and understanding of the particular patient, combined with sound judgment and co-operation between the physician and surgeon offers most hope for more live patients living worth-while lives.

\section{Acknowledgments}

I wish to thank the following who have helped in many ways with the preparation of this paper:Dr. Ian Wood for reading the typescript and Drs.
Moore and Joske for looking up the case histories mentioned. Thanks are also due to the Sisters of the Royal Melbourne Hospital and Mercy Hospital for their constant help in keeping day-today records of the charts of the patients and studying their condition; and finally to the patients themselves, many of whom assisted by adding to their case histories long written records of their own and by making observations on themselves and each other.

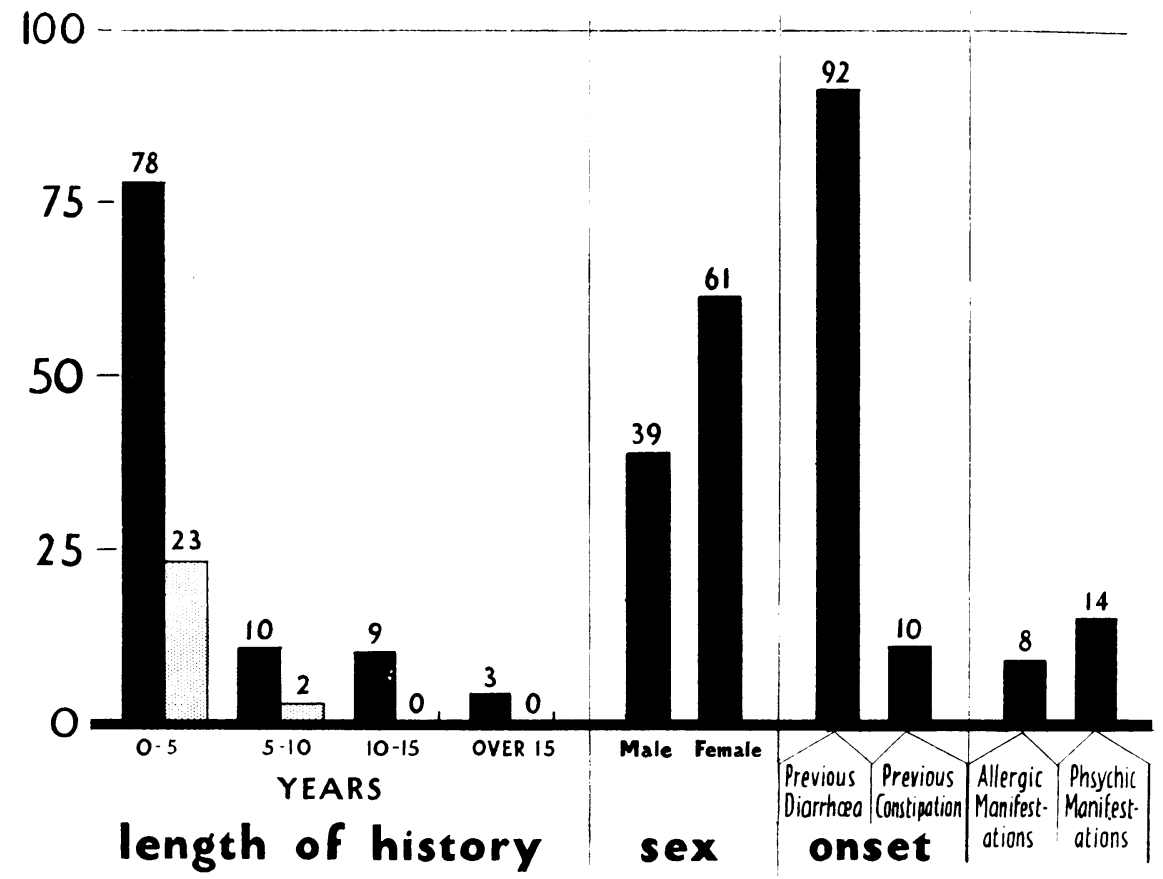

FIg. I 8.-Graphic representation of the results of a study of roo consecutive case histories of patients treated at the Royal Melbourne Hospital between 1937 and 1942 .

\section{BIBLIOGRAPHY}

BARGEN, J. ARNOLD (I9+3), "The Modern Management of Colitis,' Charles C. 'Thomas, Springfield, Illinois, L.S.A.

BOCKUS, H. L. (1944), 'Gastro-Enterology,' W. B. Saunders Co., Vol. 3 .

BUCKS'TEIN, J. (1948), 'The Digestive Tract in Roentgenology, J. B. Lippincott Co., Philadelphia, London and Montreal, p. $67 \mathrm{I}$.

CATTELL, R. B., and BOEHME, E. J. (1946), S. Clin. N.A., 26, 64I.

CATtell, R. B., and SACHs, E. (1948), 7. Am. Med. Ass., 137, 929 .

CAVE, H. W. (1946), Ann. Surg., I24, 716.

CROHN, B. C., GARLOCK, J. H., and YARNIS, H. (19+7), F. Am. Med. Ass., 134, 334.

DANIELS, G. E. (1944), Med. Clin. N.A., 28, 593.

DENNIS, C., EDDY, F, D., FRYKMAN, H., MCCARTHY, A. M., and WESTOOVER, D. (1948), Ann. Surg., 128, 479.

DENNIS, C., and EDDY, F. D. (19+7), Bull. Am. Coll. Surg. 32, No. 3, 242. N.B.-Full account in Proc. Soc. Exper. Biol. and Med., 65, 306-307, June, 1947, under title 'Evaluation of Vagotomy in Chronic Non-Specific Ulcerative Colitis.'

DEVINE, SIR H. (1945), Aust. and N.Z. F. Surg., 14, 2 I9.

DEVINE, SIR H. (1935), Med. Press and Circular, 111-119.
DEVINE, SIR H, and DEVINE, J. (19+8), Brit. Med. F., 2, I27 DEVINE, J. (19+7), M. . . Australia, 2, 750.

EDITORIAL ( I 949), Brit. Med. ₹., I, 189.

KIEFER, E. D. (1946), Surg. ('lin. N.A., 26, 579.

KIRSNER, J. B., PALMER, W. L., MAIMON, S. N., and RICKE'T's, W. E. (1948), Ұ. Amer. Med. Ass., r37, 922.

KLECKNER, M. S. (I947), Ibid., I33, 998.

LILM, R., and POR'TER, J. E. (1939), Arch. Int. Med., 63, 20 r. MAR'TIN, L. (1946), Lancet, 2, 944.

MONAGHAN, J. F. (I944), In Bockus' ' Gastro-Enterology,' W. B. Saunders (io., Philadelphia and London, Vol. 2, 549-614.

MIOR'TON, G. A. (1946), Postgrad. Med. F., 22, 253.

MURRAY, C. D. (1930), Am. F. Med. Sci., 180, 239.

PAUL, F. 'T. (1895), Brit. Med. F., I, г 136 .

POLLARD, H. M., BLOCK, M., and BACHRACH, W. H. (1947), F. Am. Med. Ass., 134, 341.

PRUDDEN, J. F., LEHMAN, W. L., MEYER, K., and (jELHORN, A. (1947), Bull. Am. Coll. S'surg., 32, 242.

STREICHER, M. H. (1947), 7. Am. Med. Ass., 134, 339

'THOREK, P. (1948), F. Internat. Coll. Surg., I I, 578.

WRIGH'T-SMITH, R. J. (1944), Roy. Melbourne Hosp. Clin. Rep., I5, II 8-II 